BASIC SCIENCE ARTICLE

\title{
Fetuin-A deficiency is associated with infantile cortical hyperostosis (Caffey disease)
}

Rona Merdler-Rabinowicz ${ }^{1}$, Anna Grinberg ${ }^{1}$, Jeffrey M. Jacobson ${ }^{2}$, Ido Somekh ${ }^{3}$, Christoph Klein ${ }^{3}$, Atar Lev ${ }^{1}$, Salama Ihsan ${ }^{4}$, Adib Habib ${ }^{5}$, Raz Somech ${ }^{1}$ and Amos J. Simon ${ }^{1,6}$

BACKGROUND: Infantile cortical hyperostosis (ICH)/Caffey disease is an inflammatory collagenopathy of infancy, manifested by subperiosteal bone hyperplasia. Genetically, ICH was linked with heterozygosity for an R836C mutation in the COL1A1 gene. Although an autosomal-recessive trait is also suspected, it has not been proven thus far.

METHODS: A case of an infant male born to consanguineous parents is reported, presenting with classical findings, course, and clinical outcome of ICH. Whole-exome sequencing (WES) was performed in order to identify a possible underlying genetic defect. RESULTS: WES analysis revealed a novel homozygous nonsense mutation in lysine 2 of fetuin-A, encoded by the ALPHA-2-HSGLYCOPROTEIN (AHSG) gene (c.A4T; p.K2X). Fetuin-A is an important regulator of bone remodeling and an inhibitor of ectopic mineralization. By enzyme-linked immunosorbent assay (ELISA), we show a complete deficiency of this protein in the patient's serum, compared to controls.

CONCLUSION: A novel homozygous nonsense mutation in AHSG gene has been found in ICH patient with a typical phenotype, resulting in fetuin-A deficiency. This finding postulates an autosomal-recessive mode of inheritance in $\mathrm{ICH}$, which, unlike the autosomal-dominant inheritance associated with COL1A1, is associated with AHSG and fetuin-A deficiency.

Pediatric Research (2019) 86:603-607; https://doi.org/10.1038/s41390-019-0499-0

\section{INTRODUCTION}

Infantile cortical hyperostosis (ICH), also known as Caffey disease or Caffey-de Toni-Silverman disease, is an inflammatory collagenopathy, manifested by subperiosteal bone hyperplasia and soft tissue swelling, most commonly affecting the mandible, clavicles, and diaphyses of long bones. ${ }^{1}$ Two different forms of the disease have been described: prenatal and infantile. The prenatal form is divided into severe and mild subtypes, based on time of onset: before and after 35 weeks of gestation, respectively. The infantile form has an onset within the first 6 months of life and in the majority of cases resolves spontaneously by the age of 2 years.

The pathophysiology of $\mathrm{ICH}$ is not completely understood. It is assumed that inflammation plays a role, as demonstrated by leukocytosis and elevated erythrocyte sedimentation rate. In addition, treatments with anti-inflammatory drugs such as glucocorticoids or nonsteroidal anti-inflammatory drugs have been proven to be helpful. ${ }^{2}$

$\mathrm{ICH}$ is considered to be a genetic disease. In several reports, researchers investigated familial cases and hypothesized that the pattern of inheritance might be autosomal dominant with incomplete penetrance and variable expressivity. ${ }^{3}$ In 2005, Gensure et al. ${ }^{4}$ confirmed the autosomal-dominant trait of $\mathrm{ICH}$ by performing a genome-wide analysis of three unrelated families presenting the disease. The researchers found a novel missense mutation in the COL1A1 gene on chromosome 17q21. This mutation is a $3040 \mathrm{C}>\mathrm{T}$ transition, resulting in the substitution of the amino acid Arginine by Cysteine at position 836 (R836C) within the helical domain of the a1 chain of type 1 collagen. This finding places $\mathrm{ICH}$ within the group of type 1 collagen-related conditions, such as osteogenesis imperfecta and Ehlers-Danlos syndrome. ${ }^{5}$ Following this report, patients with $\mathrm{ICH}$ expressing the COL1A1 mutation were reported worldwide, ${ }^{6-11}$ and even one lethal prenatal genetic case of $\mathrm{ICH}$ was described. ${ }^{12}$

Interestingly, in several $\mathrm{ICH}$ patients, this previously known mutation in COL1A1 was not identified nor were other novel mutations found for this gene., ${ }^{4,11}$ Some cases of $\mathrm{ICH}$ were suggested to be sporadic rather than genetic and were thought to differ from the familial form, as can sometimes be attributed to exposure to prostaglandin E1 and prostaglandin E2. ${ }^{13,14}$ It was also hypothesized that $\mathrm{ICH}$ might have an autosomal-recessive inheritance form ${ }^{15-17}$; nevertheless, no specific mutation has so far been described.

Here we present an infant with clinical features of $\mathrm{ICH}$, in whom the known mutation in COLIA1 was not detected. The parents of the patient were first-degree cousins, thus an autosomal-recessive inheritance was highly suspected and investigated by our team.

\section{METHODS}

Patient and data analysis

The patient record was obtained from the e-record registry of our hospital. The patient was examined by the authors. Informed

\footnotetext{
${ }^{1}$ Pediatric Department A and the Immunology Services, "Edmond and Lily Safra" Children's Hospital, Jeffrey Modell Foundation Center, Sheba Medical Center, Tel Hashomer affiliated to Sackler School of Medicine, Tel Aviv University, Tel Aviv, Israel; ${ }^{2}$ Pediatric Radiology Department, "Edmond and Lily Safra" Children's Hospital, Tel Hashomer, Israel; ${ }^{3}$ Dr. von Hauner Children's Hospital, University Hospital, Ludwig Maximilian University, Munich, Germany; ${ }^{4}$ General Health Services, Tel Hashomer, Israel; ${ }^{5}$ Saint Vincent De Paul French Hospital, Nazareth, affiliated to the Azrieli Faculty of Medicine, Bar-Ilan University, Ramat Gan, Israel and ${ }^{6}$ Sheba Cancer Research Center and Institute of Hematology, Sheba Medical Center, Tel Hashomer, Israel

Correspondence: Amos J. Simon (amos.simon@sheba.health.gov.il)
}

Received: 18 March 2019 Revised: 11 June 2019 Accepted: 29 June 2019

Published online: 9 July 2019 
consent was obtained, and all procedures performed were in accordance with the ethical standards of the institutional and/or national research committee and with the 1964 Helsinki declaration and its later amendments or comparable ethical standards.

Exome sequencing analysis and Sanger sequencing

Whole-exome sequencing (WES) was performed at the Dr. von Hauner Children's Hospital NGS facility. Genomic DNA was isolated from whole blood of the patient for generation of whole-exome libraries using the SureSelect XT Human All Exon V5+UTR or V6+UTR Kit (Agilent Technologies, USA). Barcoded libraries were sequenced on a NextSeq 500 platform (Illumina, USA) with an average coverage depth of $100 \times$. Bioinformatic analysis and subsequent filtering identified rare sequence variants. The familial segregation of this nucleotide change in the AHSG coding sequence was validated by the Sanger sequencing methodology.

Enzyme-linked immunosorbent assay (ELISA) for fetuin A Blood samples from the patient, his parents, and 19 healthy controls were collected in serum-separator tubes and allowed to coagulate for $30 \mathrm{~min}$ prior to centrifugation. Tubes were spun at 4000 RPM for $4 \mathrm{~min}$ in a non-refrigerated centrifuge. Serum was then pipetted and stored at $-20^{\circ} \mathrm{C}$. Once all samples were recruited, serum samples were thawed at room temperature for $20 \mathrm{~min}$ and assayed using the quantitative sandwich ELISA technique (R\&D Systems, Minneapolis, MN, USA). Assays were performed according to the suppliers' instructions. The assay was repeated twice.

\section{RESULTS}

Case report

A 9-week-old infant male presented to the clinic with right arm swelling that developed gradually over several weeks. No fever or systemic rash was found. There was no history of recent trauma or child abuse. The patient was the first-born child of consanguineous parents (first-degree cousins). He was born at term via cesarean section due to fetal distress. No relevant family medical history was found.

At presentation the patient was afebrile. Physical examination revealed a firmly swollen right arm, hard in consistency, without local erythema, or warmth. Radial pulse was palpable. A weak right grasping reflex was elicited. Laboratory results were notable for leukocytosis of $20 \times 10^{3} / \mathrm{ml}$ (normal range for age: $5-19 \times 10^{3} / \mathrm{ml}$ ), alkaline phosphatase of $401 \mathrm{IU} / \mathrm{l}$ (normal range for age: 145-320 $\mathrm{IU} / \mathrm{I}$ ), elevated erythrocyte sedimentation rate of $70 \mathrm{~mm} / \mathrm{h}$ (normal range for age: $3-13 \mathrm{~mm} / \mathrm{h}$ ), and C-reactive protein level of $150 \mathrm{mg} /$ $L$ (normal range for age: $0-5 \mathrm{mg} / \mathrm{l})$. Basic coagulation profile was within normal limits.

X-ray of the right arm was performed, revealing exuberant periosteal reaction along the entire shaft of the right humerus (Fig. 1a). Further evaluation included a radiographic skeletal survey, which revealed significant periosteal reaction of one scapula, one fibula, the mandible, and many ribs (Fig. 1b). Based on the clinical and radiological findings, a diagnosis of $\mathrm{ICH}$ was made. Despite the possible transient nature of $\mathrm{ICH}$, treatment with indomethacin $(5 \mathrm{mg} / \mathrm{kg}$ per day) was started, and the lesions diminished completely within several months, as was demonstrated by follow-up radiographic examinations (Fig. 1c). After 1 year of follow-up, the patient was completely well with no bone deformity and/or elevated inflammatory markers. He is still on low dose of indomethacin ( $1 \mathrm{mg} / \mathrm{kg}$ per day).

\section{Genetic evaluation}

Being a primary genetic candidate, the c.3040C>T (p.R1014C) mutation in exon 41 of $C O L 1 A 1^{4}$ was sequenced using genomic DNA obtained from peripheral blood samples of the patient and

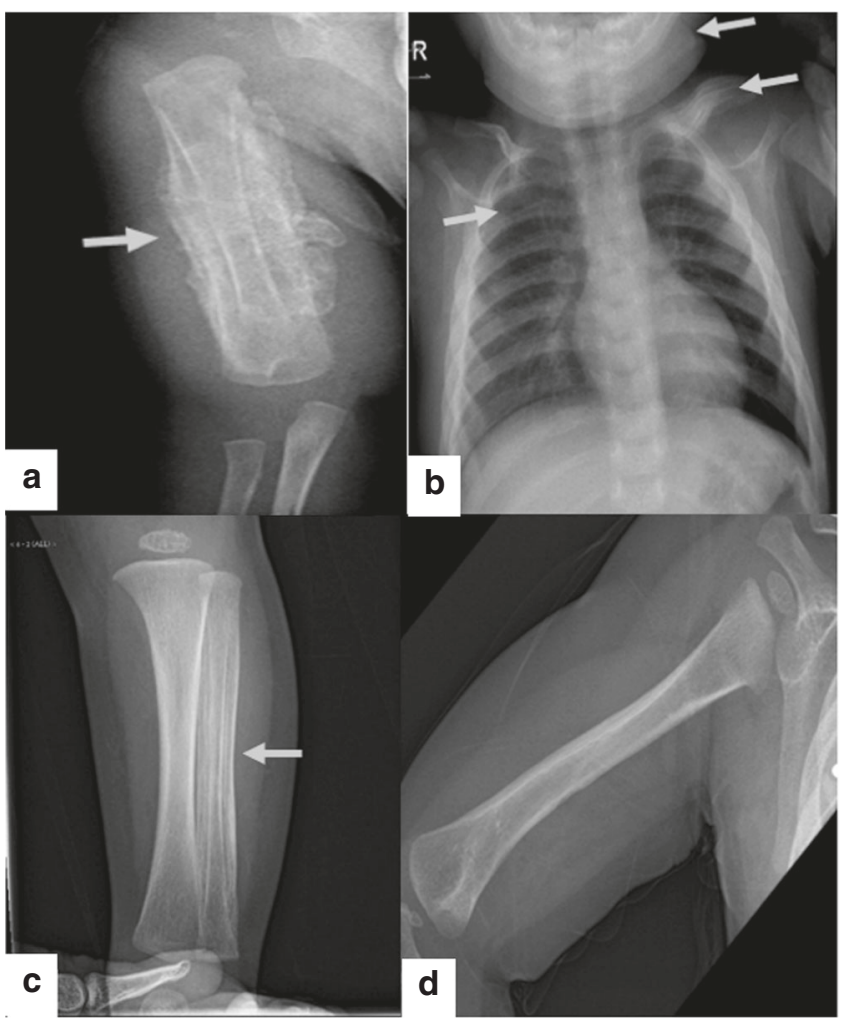

Fig. 1 Patient's radiographic examinations. a Periosteal reaction along the entire shaft of the right humerus. $\mathbf{b}$ Periosteal reaction along the left clavicle, ribs, and mandible. c Periosteal reaction along the fibula. d Complete periosteal resolution of the humerus

both parents. The mutation was neither found in the patient nor in his parents. Therefore, a WES of the patient's gDNA was performed. Sequencing yielded 59,598 variants in recessive analysis, which affect protein sequences. This list of variants was subsequently reduced to 638 rare variants, by filtering out variants present in $\geq 0.01$ of our in-house exomes and variants present with a minor allele frequency (MAF) $\geq 0.01$ in GnomAD database. Recessive analysis reduced the variants list of the patient to 20 candidate genes (Table 1). The most likely variant among these candidates that could affect bone remodeling and/ or calcification was a nonsense mutation in lysine 2 of $A H S G$ gene encoded protein, fetuin-A (c.4A>T; p.K2X). The mutation was confirmed and segregation was validated by Sanger sequencing (Fig. 2).

\section{Fetuin-A protein expression}

In order to confirm that the stop codon in position 2 of the predicted fetuin-A protein indeed causes a null protein, we detected in two separate experiments the fetuin-A serum levels of the patient, both his parents, ten age-matched healthy infants, and nine healthy adults using ELISA kit specific to serum fetuin-A (R\&D Systems, Minneapolis, MN, USA).

The mean fetuin-A serum level among the infants control group was $1803.5 \pm 515.63 \mu \mathrm{g} / \mathrm{ml}$, whereas in two independent experiments no fetuin-A protein was detected in the patient's serum, indicating the deleterious mutation $(p<0.001)$.

The serum fetuin-A levels of the parents were 592 and $626 \mu \mathrm{g} / \mathrm{ml}$ in the mother and father respectively, values which are compatible with the mean serum level of the healthy adult control group (576.1 $\pm 221.3 \mu \mathrm{g} / \mathrm{ml}$; Table 2, Fig. 3). This suggests that one wild-type (WT) allele of the AHSG gene is enough to produce the necessary amount of fetuin-A protein for normal function. 


\begin{tabular}{|c|c|c|c|c|c|c|c|}
\hline 1 & 192780677 & RGS2 & Regulator of G-protein signaling 2 & $A / G$ & Missense & 0.00015 & $\mathrm{~N}$ \\
\hline 1 & 196801023 & CFHR1 & Complement factor $\mathrm{H}$ related 1 & $\mathrm{C} / \mathrm{T}$ & Missense & 0.00003 & $\mathrm{~N}$ \\
\hline 2 & 118578823 & DDX18 & Dead box-helicase 18 & $A / G$ & Missense & 0.00003 & $\mathrm{~N}$ \\
\hline 5 & 156750984 & CYFIP2 & Cytoplasmic FMR1 interacting protein 2 & $A / G$ & Missense & 0 & $\mathrm{~N}$ \\
\hline 5 & 158743108 & IL12B & Interleukin $12 \mathrm{~B}$ & $\mathrm{G} / \mathrm{A}$ & Splice region & 0.021 & $\mathrm{~N}$ \\
\hline 5 & 158743788 & IL12B & Interleukin 12B & $\mathrm{G} / \mathrm{T}$ & Missense & 0.021 & $\mathrm{~N}$ \\
\hline 5 & 159776690 & C1QTNF2 & $\mathrm{C} 1 \mathrm{q}$ and TNF related 2 & $\mathrm{G} / \mathrm{A}$ & Missense & 0.00029 & $\mathrm{~N}$ \\
\hline 5 & 161277824 & GABRA1 & Gamma aminobutyric acid type A receptor alpha1 subunit & $A / G$ & Missense & 0 & $\mathrm{~N}$ \\
\hline 10 & 23290952 & ARMC3 & Armadillo repeat containing 3 & $\mathrm{C} / \mathrm{G}$ & Missense & 0.00001 & $\mathrm{~N}$ \\
\hline 12 & 675281 & NINJ2 & Ninjurin2 & $\mathrm{G} / \mathrm{A}$ & Missense & 0.00013 & $\mathrm{~N}$ \\
\hline 20 & 34800191 & EPB41L1 & Erythrocyte membrane protein band 4.1 like 1 & $\mathrm{C} / \mathrm{T}$ & Splice region & 0.00001 & $\mathrm{~N}$ \\
\hline 20 & 46277813 & NCOA3 & Nuclear receptor coactivator 3 & $\mathrm{C} / \mathrm{T}$ & Missense & 0.00003 & $\mathrm{~N}$ \\
\hline$x$ & 84561276 & POF1B & Premature ovarian failure, 1B & $\mathrm{C} / \mathrm{A}$ & Missense & 0 & $\mathrm{~N}$ \\
\hline Y & 21751449 & TXLNG2P & Taxilin gamma pseudogene, Y-linked & $T / G$ & Splice region & 0 & $\mathrm{~N}$ \\
\hline
\end{tabular}

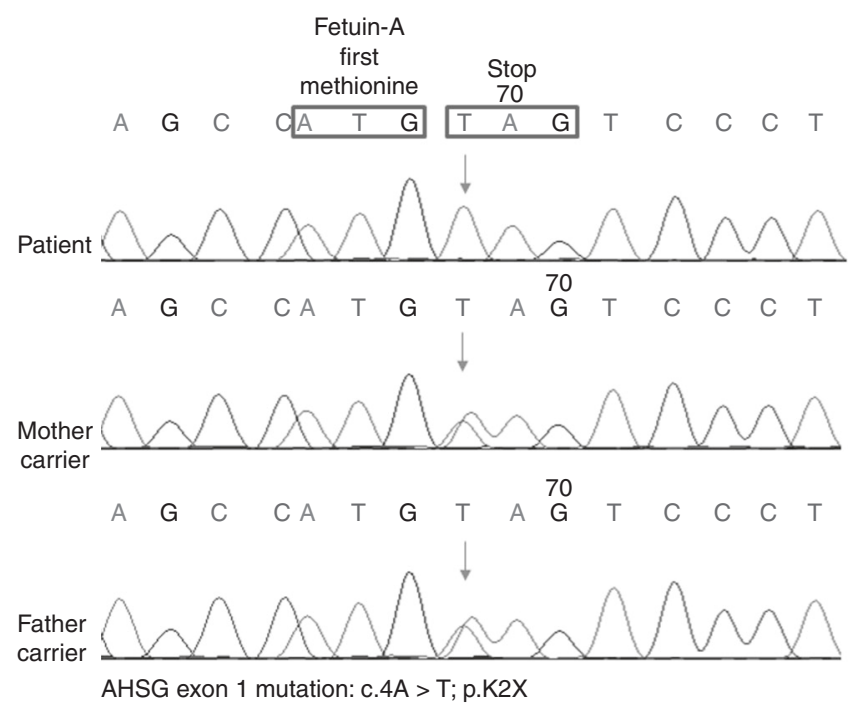

Fig. 2 Validation to the AHSG mutation. Sanger sequencing chromatograms confirmed segregation of the identified AHSG sequence variants in the patient and his parents. The first ATG codon of the encoded fetuin-A protein and the resulted TAG termination codon are boxed in red. The mutated nucleotide is marked with a blue arrow

\section{DISCUSSION}

Here we present a possible association between a novel homozygous mutation in the AHSG gene and an infant male with typical clinical manifestations of ICH. AHSG is a protein-coding gene located at chromosome $3 q 27$. The protein encoded by this gene is fetuin- $\mathrm{A} /$ alpha2-Heremans-Schmid-glycoprotein. Clinical diseases that are associated with genetic variants of AHSG include leanness, ${ }^{18}$ Alopecia-Intellectual Disability Syndrome ${ }^{19}$ Epstein-Barr virus hepatitis, ${ }^{20}$ and SARS coronavirus infection. ${ }^{21}$ Fetuin-A is also correlated to the metabolic syndrome, ${ }^{22}$ and its role as a cancer biomarker is investigated. $^{23,24}$ Fetuin-A is thought to be a regulator of normal bone calcification and an inhibitor of pathological ectopic mineralization and calcification therefore was suggested to be important for physiologic osteogenesis and bone remodeling. ${ }^{25}$

Fetuin-A is a negatively charged glycoprotein (molecular weight $52 \mathrm{kDa}$ ), produced mainly by hepatocytes, secreted by the liver into the circulation, and accumulated in mineralized bone. ${ }^{26}$ It is assumed that fetuin- $\mathrm{A}$ is produced in osteocytes as well and, to a far lesser extent, in osteoblasts, modulated by the bone-derived hormone FGF-23. ${ }^{27}$ The protein is processed from a single chain precursor into its mature circulating form, which is composed of two N-terminal cystatin protein domains and a third proline-rich C-terminal domain. The amino-terminal domain D1 enables high affinity to calcium phosphate, forming soluble protein-mineral complexes ("mineral chaperones"), thereby preventing pathological calcification at enriched mineral sites. ${ }^{28}$ In addition, fetuin-A functions as an antagonist to the transforming growth factor beta (TGF- $\beta$ ) and bone morphogenetic protein (BMP) superfamily of cytokines and in this manner controls tissue remodeling and inflammation in osteoblastic cells. Fetuin-A structure shares homology with the extracellular domain of TGF- $\beta$ receptor type II, allowing fetuin- $A$ to bind directly to TGF- $\beta 1$ and TGF- $\beta 2$ and with greater affinity to TGF- $\beta$-related BMPs (BMP-2, BMP-4, and BMP-6) and limit cytokine activity. ${ }^{29}$ In vitro studies showed that, in cultures of rat bone marrow cells, fetuin-A binds to TGF- $\beta$ cytokines and suppresses dexamethasone osteogenesis. ${ }^{29,30}$

Since the model of AHSG knockout mice (Ahsg-/-) became available, researchers examined in vivo the role of fetuin- $A$ in bone metabolism. In several studies, AHSG-deficient mice displayed severe extra-osseous calcifications of the kidney, 


\begin{tabular}{|c|c|c|c|c|}
\hline & Sample & Sex & $\begin{array}{l}\text { Age } \\
\text { (years) }\end{array}$ & $\begin{array}{l}\text { Fetuin-A level } \\
(\mu \mathrm{g} / \mathrm{ml})\end{array}$ \\
\hline \multirow[t]{9}{*}{ Adult control group } & 1 & $\mathrm{~F}$ & 40 & 482 \\
\hline & 2 & $\mathrm{~F}$ & 39 & 761 \\
\hline & 3 & M & 30 & 875 \\
\hline & 4 & $\mathrm{~F}$ & 20 & 693 \\
\hline & 5 & M & 33 & 829 \\
\hline & 6 & M & 44 & 409 \\
\hline & 7 & $\mathrm{~F}$ & 50 & 420 \\
\hline & 8 & M & 28 & 227 \\
\hline & 9 & $\mathrm{~F}$ & 36 & 489 \\
\hline \multirow[t]{10}{*}{ Infant control group } & 1 & M & 2 & 1796 \\
\hline & 2 & $\mathrm{~F}$ & 1.5 & 1607 \\
\hline & 3 & $\mathrm{~F}$ & 2 & 1002 \\
\hline & 4 & M & 0.5 & 2071 \\
\hline & 5 & $\mathrm{~F}$ & 5 & 1722 \\
\hline & 6 & M & 4 & 1140 \\
\hline & 7 & M & 4 & 2234 \\
\hline & 8 & M & 5 & 2497 \\
\hline & 9 & $\mathrm{~F}$ & 6 & 1502 \\
\hline & 10 & $\mathrm{~F}$ & 4 & 2464 \\
\hline \multirow[t]{4}{*}{ Patient's parents } & Mother (1) & $\mathrm{F}$ & 21 & 535 \\
\hline & Mother (2) & $\mathrm{F}$ & 21 & 649 \\
\hline & Father (1) & M & 24 & 603 \\
\hline & Father (2) & $M$ & 24 & 649 \\
\hline \multirow[t]{2}{*}{ Patient } & -1 & $M$ & 1 & Negative \\
\hline & -2 & $M$ & 1 & Negative \\
\hline
\end{tabular}

AHSG ALPHA-2-HS-GLYCOPROTEIN, ELISA enzyme-linked immunosorbent assay

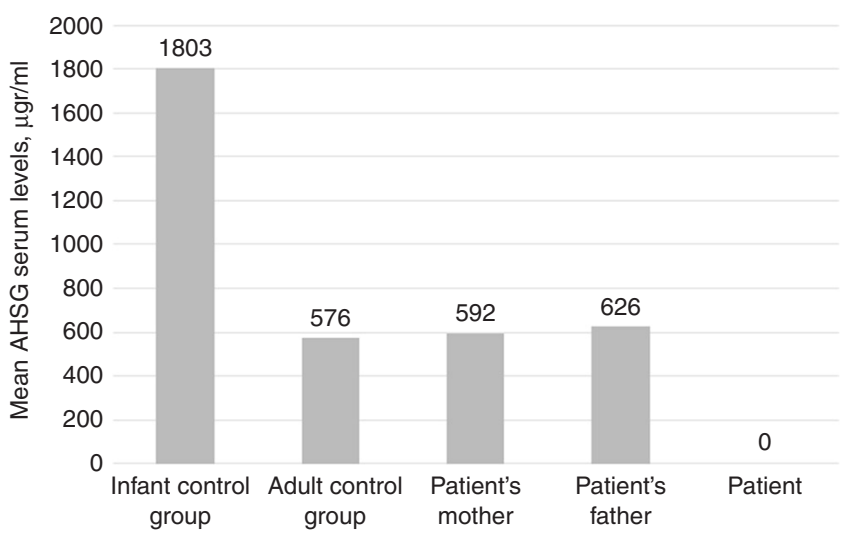

Fig. 3 Fetuin-A protein levels in the sera. The fetuin-A serum levels of the patient, both his parents, ten age-matched healthy infants, and nine healthy adults were measured, using the enzyme-linked immunosorbent assay kit specific to serum fetuin-A (R\&D Systems, Minneapolis, MN, USA). The results are presented in $\mu \mathrm{g} / \mathrm{ml}$

heart, and lung, emphasizing the role of fetuin-A as an inhibitor of ectopic mineralization. ${ }^{31,32}$ In other studies, AHSG-deficient mice presented a variety of pathological manifestations in physiological sites of mineralization such as long bones and growth plates: Seto et al. ${ }^{33}$ showed that $A H S G$-deficient mice display increased cortical thickness in the femur, with increased mineral content in the growth plate cartilage matrix, a site of vigorous physiological mineralization. Rittenberg et al. ${ }^{34}$ implanted human native BMP into hindquarter muscles of mice and showed that the ratio of cortical to cancellous bone was more than two-fold higher in Ahsg-/- mice compared to WT and also presented higher incidence of immature bone islands ("satellite ossification"). Szweras et al. $^{35}$ showed that mice lacking ASHG protein display growth plate defects, increased bone formation including cortical thickening, and enhanced cytokine-dependent osteogenesis. All these findings in mice highly point to a possible role of AHSG deficiency in the pathophysiology of Caffey disease, which is characterized by subperiosteal bone hyperplasia.

Clinically, elevated serum levels of fetuin-A were found to be correlated with a mild form of osteogenesis imperfecta, ${ }^{36}$ whereas depressed levels of fetuin-A were observed in increased bone turnover conditions, such as Paget's disease. ${ }^{37}$

Interestingly, a novel homozygous stop codon mutation in AHSG gene was found in our presented case who had typical features of infantile Caffey disease. This resulted in no production of fetuin-A in the patient, as detected by ELISA test. Taking into consideration the importance of fetuin-A in bone metabolism, we highly suspect that this AHSG gene defect is the cause of the $\mathrm{ICH}$ phenotype in our patient. These findings also support the theory that $\mathrm{ICH}$ can be inherited in an autosomal-recessive manner. Our discovery raises the possibility of potential treatments for $\mathrm{ICH}$. For instance, in patients with pseudoxanthoma elasticum, a hereditary disease of ectopic mineralization in soft connective tissues caused by a known mutation in $A B C C 6$ gene, circulatory fetuin- $A$ was found to be reduced. ${ }^{38}$ Jiang et al. $^{39}$ suggested that normalization of serum fetuin-A, either through gene therapy or by direct protein delivery to the circulation, can be used to treat the disease. In this manner, based on our study, fetuin-A should also be considered as a treatment for $\mathrm{ICH}$.

Our study has several limitations; we report only an association between fetuin-A deficiency and ICH phenotype, but no in vivo experiment was conducted in order to prove causation. However, as described above, previous studies that investigated AHSG knockout mice showed bone hyperplasia and cortical thickening resembling $\mathrm{ICH}$ manifestations. The novel stop codon mutation that we described causes zero production of fetuin-A. In other words, it is equivalent to knocking out the AHSG gene. Thus we consider this mutation to be the cause of $\mathrm{ICH}$ in our patient. We, therefore, propose that additional Caffey disease patients with non-COL1A1 defects will be assessed for fetuin-A deficiency. It can be argued that our patient might have a "Caffey-like" disease with manifestations imitating the classic infantile Caffey disease described in the literature. However, the classic presentation in our patient, including the laboratory and imaging findings, as well as the prompt resolution of the symptoms, are all consistent with $\mathrm{ICH}$, therefore we highly recommend additional $\mathrm{ICH}$ patients with non-COL1A1 defects to be assessed for fetuin-A deficiency.

In conclusion, $\mathrm{ICH}$ is an underdiagnosed collagenopathy of infancy; hence, clinicians in general and pediatricians in particular should be aware of its unique presentation and proper management. ICH has a strong genetic basis; while an autosomal-dominant mutation in the COL1A1 gene was previously reported, we are the first to report an association between a novel autosomal-recessive mutation in the AHSG gene and $\mathrm{ICH}$. This homozygous nonsense mutation in lysine 2 of the AHSG encoded protein (c.4A>T; p.K2X) caused null production of fetuin-A, revealing the importance of this protein in the pathogenesis of $\mathrm{ICH}$. Treatment approaches for increasing fetuin-A levels among ICH patients should be considered and further investigated. 


\section{ACKNOWLEDGEMENTS}

We thank the patient's family for their cooperation. We thank the Care-for-Rare Foundation and the DAAD for supporting the study.

\section{AUTHOR CONTRIBUTIONS}

R.M.-R., A.R., A.L. and A.J.S. designed, performed, and analyzed experiments; I.S. and C.K. conducted WES study and analyzed the results; J.J. diagnosed imaging and reviewed manuscript; S.I., A.A. and R.S. followed, diagnosed, and treated the patient; R.M.-R., A.J.S. and R.S. drafted the manuscript and supervised the experiments.

\section{ADDITIONAL INFORMATION}

Competing interests: The authors declare no competing interests.

Publisher's note: Springer Nature remains neutral with regard to jurisdictional claims in published maps and institutional affiliations.

\section{REFERENCES}

1. Caffey, J. Infantile cortical hyperostosis; a review of the clinical and radiographic features. Proc. R. Soc. Med. 50, 347-354 (1957).

2. Heyman, E., Laver, J. \& Beer, S. Prostaglandin synthetase inhibitor in Caffey disease. J. Pedia. 101, 314 (1982).

3. Saul, R. A., Lee, W. H. \& Stevenson, R. E. Caffey's disease revisited. Further evidence for autosomal dominant inheritance with incomplete penetrance. Am. J. Dis. Child. 136, 55-60 (1982).

4. Gensure, R. C. et al. A novel COL1A1 mutation in infantile cortical hyperostosis (Caffey disease) expands the spectrum of collagen-related disorders. J. Clin. Invest. 115, 1250-1257 (2005).

5. Glorieux, F. H. Caffey disease: an unlikely collagenopathy. J. Clin. Invest. 115, 1142-1144 (2005).

6. Cho, T. J. et al. The c.3040C $>$ T mutation in COL1A1 is recurrent in Korean patients with infantile cortical hyperostosis (Caffey disease). J. Hum. Genet. 53, 947-949 (2008).

7. Ranganath, P., Laine, C. M., Gupta, D., Makitie, O. \& Phadke, S. R. COL1A1 mutation in an Indian child with Caffey disease. Indian J. Pediatr. 78, 877-879 (2011).

8. Cerruti-Mainardi, P. et al. Infantile cortical hyperostosis and COL1A1 mutation in four generations. Eur. J. Pediatr. 170, 1385-1390 (2011).

9. Prior, A. R., Moldovan, O., Azevedo, A. \& Moniz, C. Caffey disease in neonatal period: the importance of the family! BMJ Case Rep. 2012, bcr2012006996 (2012).

10. Spranger, J. W. \& Lausch, E. Hyperostosis in siblings. S Afr. Med. J. 106, S98-S99 (2016).

11. Kitaoka, T. et al. Two Japanese familial cases of Caffey disease with and without the common COL1A1 mutation and normal bone density, and review of the literature. Eur. J. Pediatr. 173, 799-804 (2014).

12. Kamoun-Goldrat, A. et al. Prenatal cortical hyperostosis with COL1A1 gene mutation. Am. J. Med. Genet. A 146A, 1820-1824 (2008).

13. Estes, K., Nowicki, M. \& Bishop, P. Cortical hyperostosis secondary to prostaglandin E1 therapy. J. Pediatr. 151, 441e441 (2007). 441.

14. Woo, K., Emery, J. \& Peabody, J. Cortical hyperostosis: a complication of prolonged prostaglandin infusion in infants awaiting cardiac transplantation. Pediatrics 93, 417-420 (1994).

15. Sidbury, J. B. Jr. \& Sidbury, J. B. Infantile cortical hyperostosis; an inquiry into the etiology and pathogenesis. N. Engl. J. Med. 250, 309-314 (1954).

16. Barba, W. P. \& Freriks, D. J. The familial occurrence of infantile cortical hyperostosis in utero. J. Pediatr. 42, 141-150 (1953).

17. Schweiger, S. et al. Antenatal onset of cortical hyperostosis (Caffey disease): case report and review. Am. J. Med. Genet. A 120A, 547-552 (2003).

18. Lavebratt, C., Wahlqvist, S., Nordfors, L., Hoffstedt, J. \& Arner, P. AHSG gene variant is associated with leanness among Swedish men. Hum. Genet. 117, 54-60 (2005).

19. Reza Sailani, M. et al. Association of AHSG with alopecia and mental retardation (APMR) syndrome. Hum. Genet. 136, 287-296 (2017).

20. Kalabay, L. et al. Human fetuin/alpha2HS-glycoprotein level as a novel indicator of liver cell function and short-term mortality in patients with liver cirrhosis and liver cancer. Eur. J. Gastroenterol. Hepatol. 14, 389-394 (2002).

21. Zhu, X. et al. Genetic variation of the human alpha-2-Heremans-Schmid glycoprotein (AHSG) gene associated with the risk of SARS-CoV infection. PLOS ONE 6, e23730 (2011)

22. Dabrowska, A. M., Tarach, J. S., Wojtysiak-Duma, B. \& Duma, D. Fetuin-A (AHSG) and its usefulness in clinical practice. Review of the literature. Biomed. Pap. Med Fac. Univ. Palacky. Olomouc Czech Repub. 159, 352-359 (2015).

23. Abdullah, M. I., Lee, C. C., Mat Junit, S., Ng, K. L. \& Hashim, O. H. Tissue and serum samples of patients with papillary thyroid cancer with and without benign background demonstrate different altered expression of proteins. PeerJ 4, e2450 (2016).

24. Shi, F. et al. Identification of serum proteins AHSG, FGA and APOA-I as diagnostic biomarkers for gastric cancer. Clin. Proteomics 15, 18 (2018).

25. Jahnen-Dechent, W., Heiss, A., Schafer, C. \& Ketteler, M. Fetuin-A regulation of calcified matrix metabolism. Circ. Res. 108, 1494-1509 (2011).

26. Dickson, I. R., Poole, A. R. \& Veis, A. Localisation of plasma alpha2HS glycoprotein in mineralising human bone. Nature 256, 430-432 (1975).

27. Mattinzoli, D. et al. FGF23-regulated production of Fetuin-A (AHSG) in osteocytes. Bone 83, 35-47 (2016).

28. Jahnen-Dechent, W., Schafer, C., Ketteler, M. \& McKee, M. D. Mineral chaperones: a role for fetuin-A and osteopontin in the inhibition and regression of pathologic calcification. J. Mol. Med. (Berl.) 86, 379-389 (2008).

29. Demetriou, M., Binkert, C., Sukhu, B., Tenenbaum, H. C. \& Dennis, J. W. Fetuin/ alpha2-HS glycoprotein is a transforming growth factor-beta type II receptor mimic and cytokine antagonist. J. Biol. Chem. 271, 12755-12761 (1996).

30. Binkert, C. et al. Regulation of osteogenesis by fetuin. J. Biol. Chem. 274 28514-28520 (1999).

31. Schafer, C. et al. The serum protein alpha 2-Heremans-Schmid glycoprotein/ fetuin-A is a systemically acting inhibitor of ectopic calcification. J. Clin. Invest. 112, 357-366 (2003).

32. Westenfeld, R. et al. Fetuin-A (AHSG) prevents extraosseous calcification induced by uraemia and phosphate challenge in mice. Nephrol. Dial. Transpl. 22, 1537-1546 (2007).

33. Seto, J. et al. Accelerated growth plate mineralization and foreshortened proximal limb bones in fetuin-A knockout mice. PLOS ONE 7, e47338 (2012).

34. Rittenberg, B. et al. Regulation of BMP-induced ectopic bone formation by Ahsg. J. Orthop. Res. 23, 653-662 (2005).

35. Szweras, M. et al. alpha 2-HS glycoprotein/fetuin, a transforming growth factorbeta/bone morphogenetic protein antagonist, regulates postnatal bone growth and remodeling. J. Biol. Chem. 277, 19991-19997 (2002).

36. Dickson, I. R., Bagga, M. \& Paterson, C. R. Variations in the serum concentration and urine excretion of alpha $2 \mathrm{HS}$-glycoprotein, a bone-related protein, in normal individuals and in patients with osteogenesis imperfecta. Calcif. Tissue Int. 35, 16-20 (1983).

37. Ashton, B. A. \& Smith, R. Plasma alpha $2 \mathrm{HS}$-glycoprotein concentration in Paget's disease of bone: its possible significance. Clin. Sci. (Lond.) 58, 435-438 (1980).

38. Hendig, D. et al. Role of serum fetuin-A, a major inhibitor of systemic calcification, in pseudoxanthoma elasticum. Clin. Chem. 52, 227-234 (2006).

39. Jiang, Q., Dibra, F., Lee, M. D., Oldenburg, R. \& Uitto, J. Overexpression of fetuin-a counteracts ectopic mineralization in a mouse model of pseudoxanthoma elasticum (abcc6(-/-)). J. Invest. Dermatol. 130, 1288-1296 (2010). 